\title{
ANÁLISE DA DEGRADAÇÃO AMBIENTAL OCORRIDA NA BACIA HIDROGRÁFICA DO UERÊ/MS
}

Paulo Henrique Vieira ${ }^{1}$

\section{Aline Cristina Alves da Silva²}

\section{Patricia Helena Mirandola ${ }^{3}$}

Resumo: O presente trabalho tem como objetivo a análise da degradação ambiental que ocorre na bacia hidrográfica do Uerê, que fica localizada no município de Bataguassu no estado de Mato Grosso do Sul, para tal análise será utilizado o SIG (Sistema de Informação Geográfico), neste caso específico sera utilizado o SPRING 5.1.2, para o auxilio das análises dos processos degradantes do local de estudo. O uso dessa ferramenta tem com enfoque demonstrar a importância que essa tecnologia possui na análise espacial. Para alcançar tais metas foi preciso utilizar alguns procedimentos metodológicos: Trabalhos de Gabinete visa um resumo bibliográfico que tem como pesquisa o tema de estudo do trabalho; Abordagem Sistêmica voltada para hierarquização do componente estudado; Utilização do Geoprocessamento parte que subdividida em três componentes Pré-Geoprocessamento, Geoprocessamento e Pós-Geoprocessamento; Saídas de Campo consiste em ir ao local de estudo para conhecimento da área estudada; Divulgação dos Resultados esta é última etapa que aborda a organização dos dados em um banco de dados para a divulgação dos dados e informações geradas. Bacias hidrográficas são locais de suma importância na análise geográfica por neste local encontrar-se a interação do homem com o sistema ambiental.

Palavras-chave: Degradação Ambiental, Bacia Hidrográfica, Tecnologia

\footnotetext{
${ }_{1}^{1}$ Pós-Graduando no curso de geografia da UFMS/CPTL. paulohenrique.vieira@yahoo.com.br 2Pós-Graduanda no curso de geografia da UFMS/CPTL. alinegeo_ufms@yahoo.com.br

3 Prof ${ }^{-a}$ Draㅡ do curso de geografia da UFMS/CPTL. patriciaufmsgeografia@gmail.com
} 


\section{INTRODUÇÃO}

No intuito de promover alguma forma de desenvolvimento para determinados locais a sociedade, seja em locais urbanos ou rurais, vem causando impactos nos sistemas em que vivem. Impactos estes que podem ser vistos com um mau manejo do solo, desmatamento, queimadas, erosões, poluição dos recursos hídricos dentre outras formas de degradação do ambiente. Muitas vezes essas modificações ocorrem tendo como conceito a importância do desenvolvimento local, sem se preocupar com os sistemas ambientais.

Nesse contexto torna-se necessário acompanhar o desenvolvimento local acompanhando como vem sendo utilizado o espaço geográfico. Apontar falhas no planejamento e gestão da área e dos recursos voltados a ela e oferecidos por ela, racionalizando a exploração dos bens disponíveis e direcionando a ocupação da terra para fins mais adequados (Silva, Schulz e Camargo, 2007). Para que assim possa ser possível manter um equilíbrio ambiental.

Dentre os locais onde um planejamento torna-se necessária devida as modificações que ocorrem são as bacias hidrográficas espaço este complexo onde ocorrem as interações do meio ambiente com as atividades antrópicas. As bacias hidrográficas podem ser definidas como uma área drenada por um curso principal e seus afluentes, podendo ser delimitada por suas cotas altimétricas (Botelho, 1999).

O local de estudo do trabalho é a bacia hidrográfica do Uerê, localizada do município de Bataguassu no estado do Mato Grosso do Sul. Em tal bacia hidrográfica encontra-se degradação ambiental em diversos locais do seu percurso, dentre essas degradações ambientais destaca-se a retirada de cobertura vegetal, assoreamento do córrego e principalmente processos erosivos que causam um desequilíbrio ambiental na bacia hidrográfica e comprometem assim a qualidade ambiental da mesma.

Dentre os processos de degradação que vem ocorrendo na área o de maior influência na qualidade ambiental do córrego é a erosão definida como desagregação e remoção de partículas do solo ou fragmentos e partículas de rochas pela ação combinada da gravidade com a água, vento gelo e/ou organismos (plantas e animais) (IPT, 1986 
apud TOMINAGA, SANTORO \& AMARAL). Entre os fatores que causam a erosão destaca-se o clima, natureza do solo, declividade do terreno e manejo do solo.

Há um longo tempo o depauperamento dos solos preocupam os pesquisadores, principalmente os estudiosos de bacias hidrográficas aumentando o número de trabalhos tendo como objetivo essa área, o total de trabalhos que adotaram B.H. como célula básica foi sete vezes maior na última década (1990/2000) em comparação à década anterior (1980/1990) (Botelho e Silva 2004). Geralmente nota-se que, quando há consequências danosas resultantes da erosão, a causa é o desrespeito dos usuários da terra para com a própria terra, buscando uma exploração desta, acima da sua capacidade de manejo de uso, tendo como consequência a deposição de sedimentos, ou seja, o assoreamento dos córregos

Uma ferramenta que auxilia os pesquisadores nas análises de degradação ambiental é o SIG ideal para integrar dados, informações e cartas de naturezas e escalas diferentes (Paranhos Filho, 2008), além de poder demonstrar através de mapas como vem sendo ocupado a área analisada. O SIG deve ser compreendido como uma vigorosa ferramenta para apoiar a tomada de decisão por parte do usuário. A sua estrutura deve, nesse sentido, ser muito bem planejada para que a interação homem-máquina se dê de maneira eficiente e atenda às necessidades dos usuários (FITZ, 2008).

O que pretende com este trabalho é analisar os processos de degradação ambiental que vem ocorrendo na área tendo como enfoque medidas de recuperação dos pontos analisados ou sua recuperação. A recuperação de um canal significa, de forma simples, o retorno às condições anteriores à degradação ambiental (Guerra e Cunha, 2009).

\section{LOCALIZAÇÃo DA ÁREA DE ESTUDO}

A bacia hidrográfica do Uerê, localizado no município de Bataguassu/MS, este último localiza-se na costa leste do estado. Bataguassu é conhecida como a cidade Portal do MS, e faz divisa com o estado de São Paulo, cidade de Presidente Epitácio. O município fica a uma distância de $335 \mathrm{~km}$ de Campo Grande, capital do estado de Mato Grosso do Sul. 
A bacia hidrográfica fica na parte norte do município próximo ao sítio urbano do de Bataguassu.

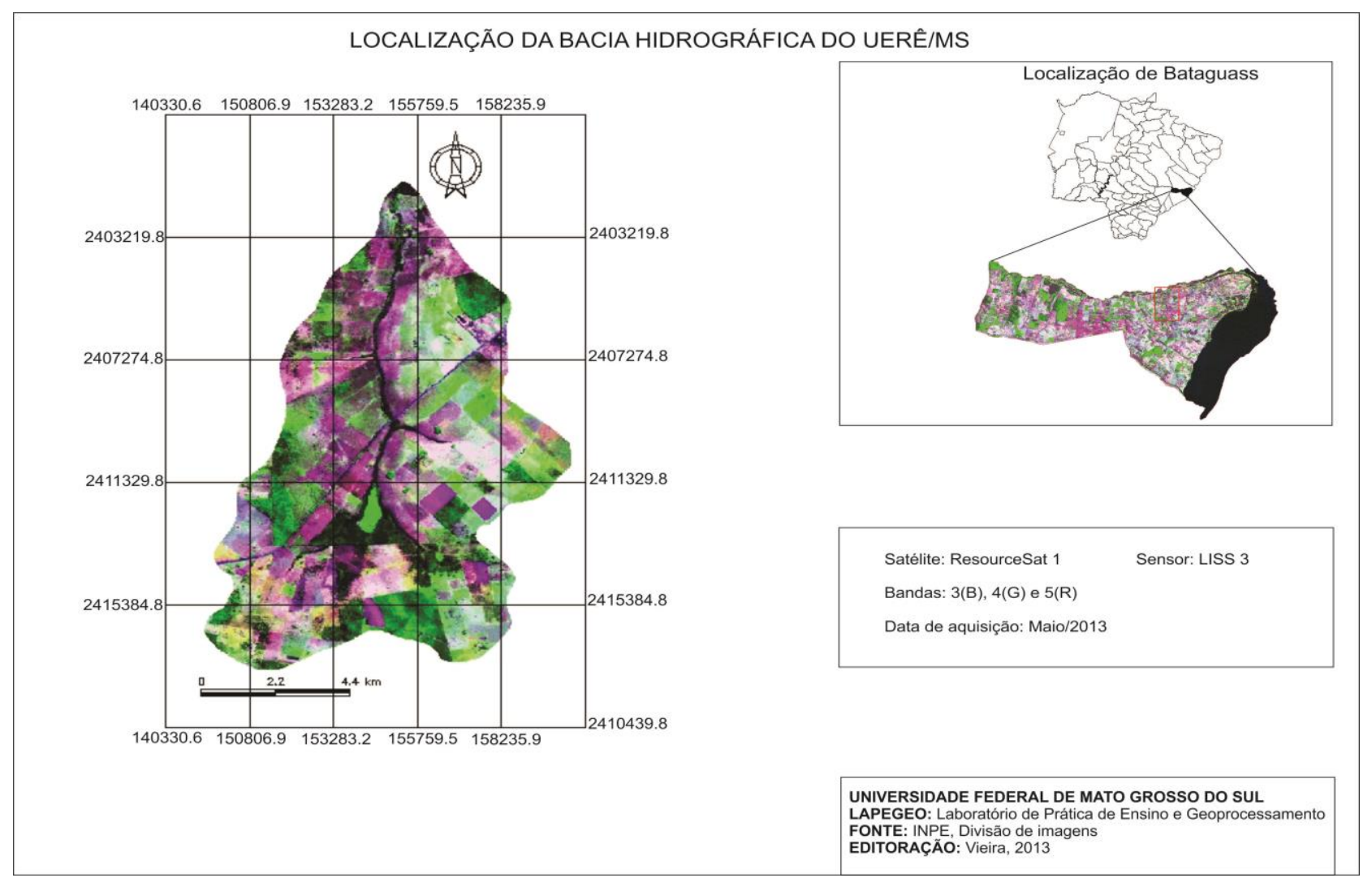

Figura 1 - Localização da bacia hidrográfica do Uerê/MS

\section{DESENVOLVIMENTO}

A temática que este trabalho se propôs desenvolver tem como base a escolha de uma abordagem qualitativa.

Foi escolhida a pesquisa qualitativa para abordar tema proposto que se baseia na observação e levantamento de aspectos do problema, diferente da pesquisa quantitativa que contabiliza, por exemplo, o excesso de sedimentos e número de erosões. Enquanto a metodologia quantitativa supõe uma observação de objetos comparados entre si, os métodos qualitativos enfatizavam as especificidades de um fenômeno em termos de suas origens e de sua razão de se (MAGALHÃES, 2007). 


\section{Then Fórum Ambiental \\ da Alta Paulista

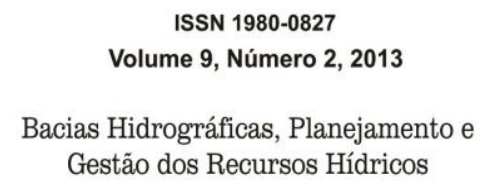

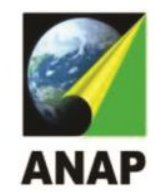

Apoia-se na abordagem sistêmica de Bertalanffy (1977), como referencial para o conjunto da bacia hidrográfica do Uerê, considerada assim como um sistema ambiental. $\mathrm{E}$ também se baseiam nos procedimentos metodológicos de Goés e Xavier da Silva (1996).

Para atingir os objetivos e desenvolver as questões centrais propostas a metodologia foi dividida nas seguintes atividades:

Atividade 1 - Trabalhos de Gabinete: As Primeiras etapas de atividades de gabinetes constam de revisão bibliográfica, levantamento de dados referentes a espacialização da bacia hidrográfica, cuja finalidade será obter informações referentes ao meio natural que subsidiarão os mapeamentos e análise acerca do tema.

Atividade 2 - Abordagem Sistêmica: O presente trabalho apoia-se na abordagem sistêmica, considerando o ambiente como um sistema ambiental, baseado na perspectiva de Bertalanffy (1977), propondo o entendimento deste sistema ambiental, a partir da Teoria Geral dos Sistemas. Voltado para o entendimento da hierarquização e individualização dos componentes sendo assim:

- Sistema: Bacia Hidrográfica do Rio Paraná

- Subsistema: Bacia Hidrográfica do Rio Pardo

- $\quad$ Parte Componente: Bacia Hidrográfica do Uerê

Nesse sentido, as bacias hidrográficas permitem o conhecimento e certo grau de controle dos agentes envolvidos na produção do espaço da área de estudo. A forma que se encontra o sistema ambiental é devido às atividades feitas nos períodos anteriores, tanto no núcleo da área de estudo como nas áreas que o compõem.

Atividade 3 - Utilização do Geoprocessamento: Etapa baseada no enfoque metodológico de Goés e Xavier da Silva (1996)

Pré-Geoprocessamento (organização dos dados adquiridos em banco de dados digital), Geoprocessamento (tratamento e análise dos dados digitais através de um SIG), e o Pós Geoprocessamento (confecção dos mapas legendas, escalas, etc), essa subdivisão demonstra claramente a criação de mapas desde a introdução de dados até a confecção de mapas, as cores utilizadas nos mapas são aquelas definidas pelo manual técnico de uso e ocupação da terra do IBGE (2006).

Atividade 4 - Saídas de Campo: As saídas de campo "in loco" são feitas na área de estudo, tendo assim uma noção dos problemas existentes e evita equívocos nas análises 
e mapeamentos. Nesta etapa utiliza-se o registro fotográfico e o GPS (Sistema de Posicionamento Global), criando assim um material com fotos (da degradação ambiental), georreferenciado.

Atividade 5 - Divulgação dos Resultados: Consiste na organização das informações geradas em banco de dados digitais para divulgação.

\section{RESULTADOS}

O mapa de uso e ocupação da terra produzido da bacia hidrográfica do Uerê mostra como o solo da região é ocupado, e as interferências desse tipo de classe de cobertura da terra pode ter no entorno da bacia. As cores utilizadas em cada classe de cobertura são recomendadas pelo manual técnico de uso e ocupação da terra do IBGE de 2006.

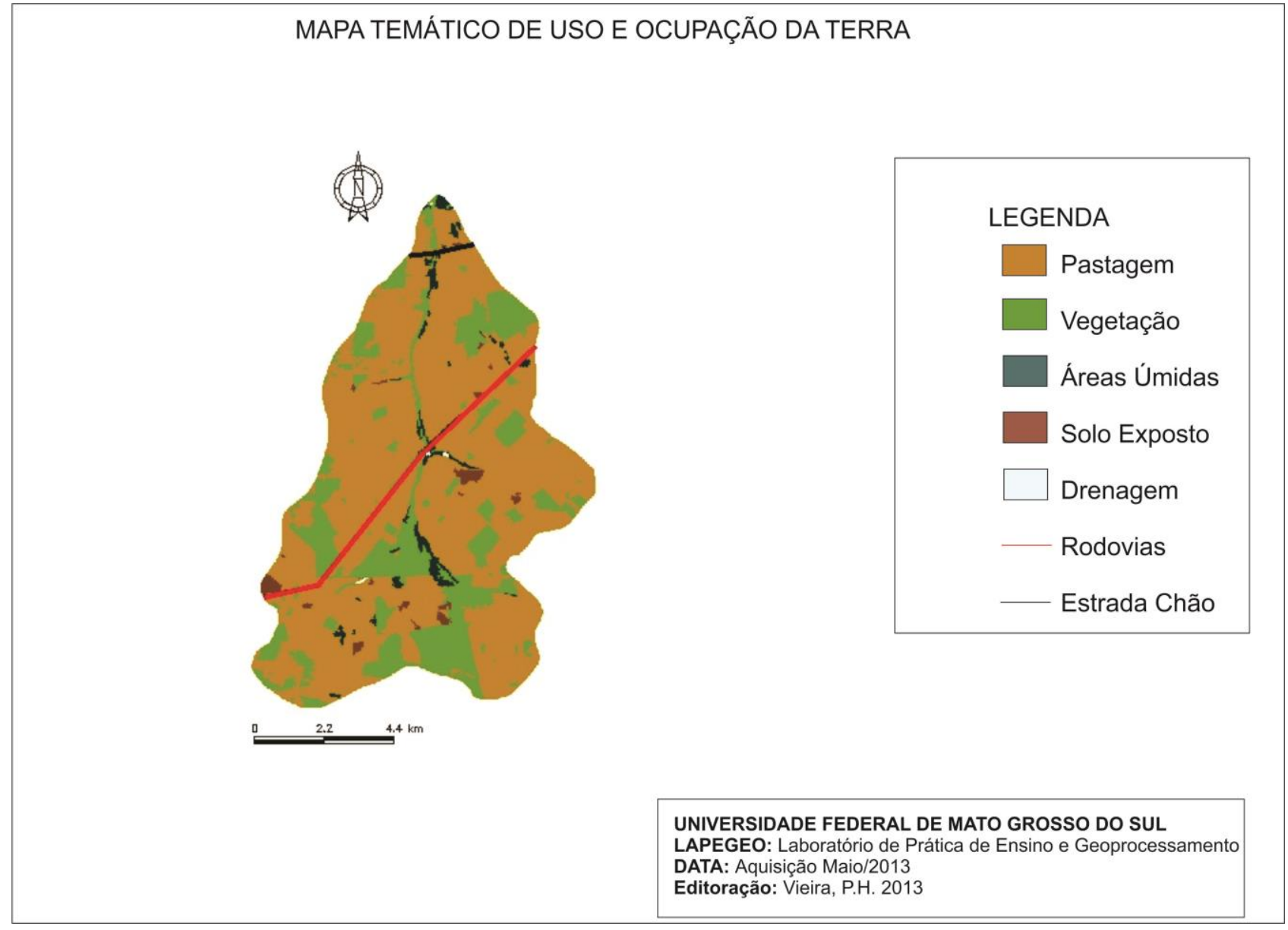

Figura 2 - Mapa de uso e ocupação da terra da bacia hidrográfica do Uerê/MS 


\section{Then

Como se pode observar no mapa a predominância da área da bacia hidrográfica é de pastagem, uma das possíveis explicações por essa predominância é por Bataguassu ter uma economia voltada pela agropecuária com a presença do frigorifico MARFRIG. Com o pisoteio do gado no entorno da região e sem medidas preventivas, os processos erosivos intensificam.

Vegetação natura encontra-se em sua grande maioria próximo as nascentes existentes, sendo a segunda classe com maior extensão territorial.

As classes de área úmida que são parcelas do território próximo ao curso hídrico e o solo exposto se apresentam em pequenas regiões, abaixo se encontra um quadro com as percentagens territoriais de cada classe de cobertura.

Quadro 1 - Percentagem territorial das classes de cobertura

\begin{tabular}{|c|c|}
\hline Classe de cobertura & Percentagem (\%) \\
\hline Pastagem & 73 \\
\hline Drenagem & 1 \\
\hline Vegetação & 23 \\
\hline Áreas Úmidas & 2 \\
\hline Solo Exposto & 1 \\
\hline Total & 100 \\
\hline
\end{tabular}

Com a análise do quadro observa-se que pastagem e a vegetação natural possuem juntas $96 \%$ do território da bacia, enquanto as outras classes possuem valores irrisórios. Abaixo serão mostrados pontos analisados da bacia hidrográfica onde encontra processos de degradação. 


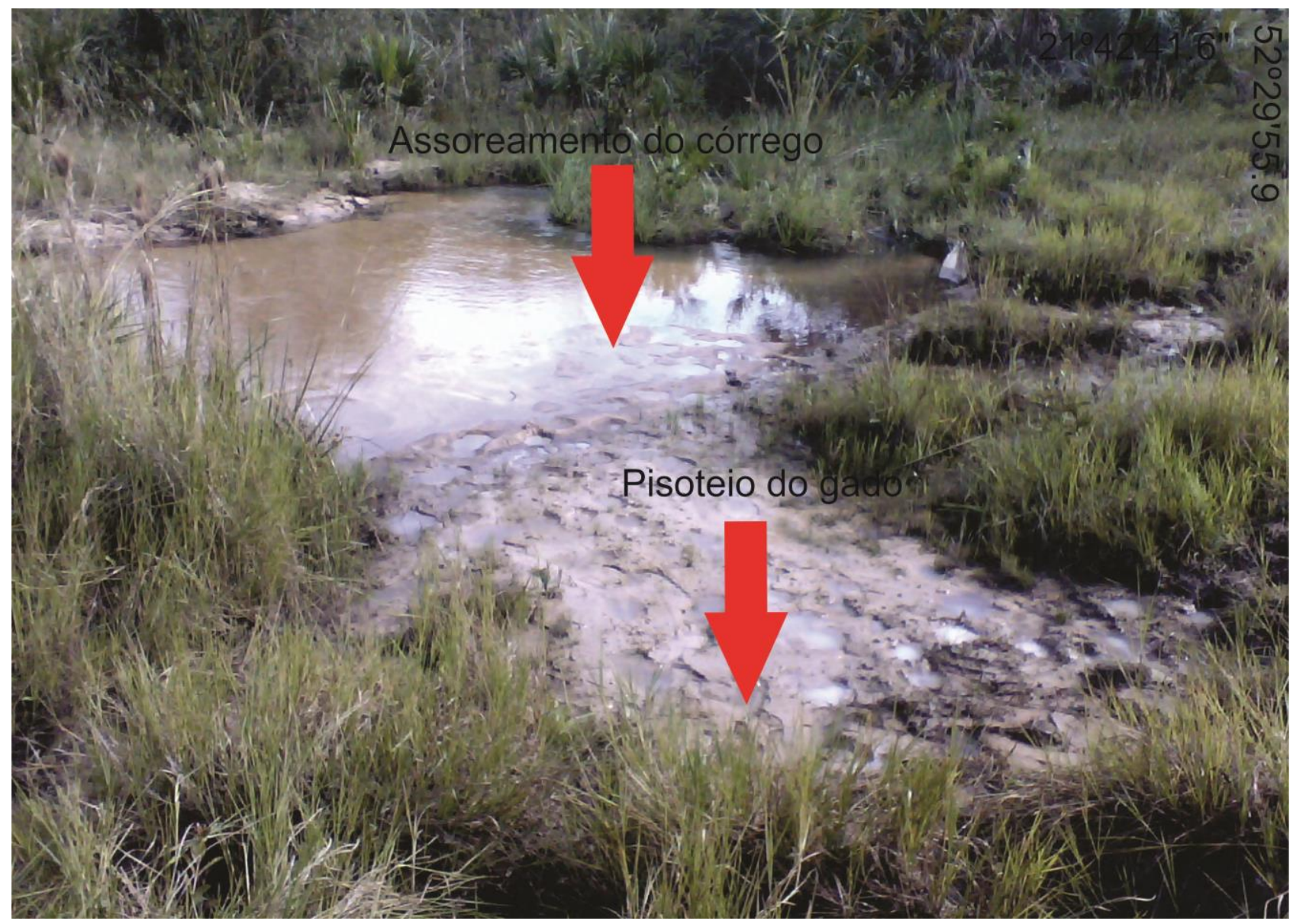

Figura 3 - Processos de degradação ambiental

$\mathrm{Na}$ foto acima se verifica a falta de mata ciliar em parte do trecho do córrego, onde se observa o pisoteio do gado, aumentando assim o processo erosivo ocasionando assoreamento do córrego, faltando assim medidas preventivas para que o pisoteio do gado não intensifique nessa área. 


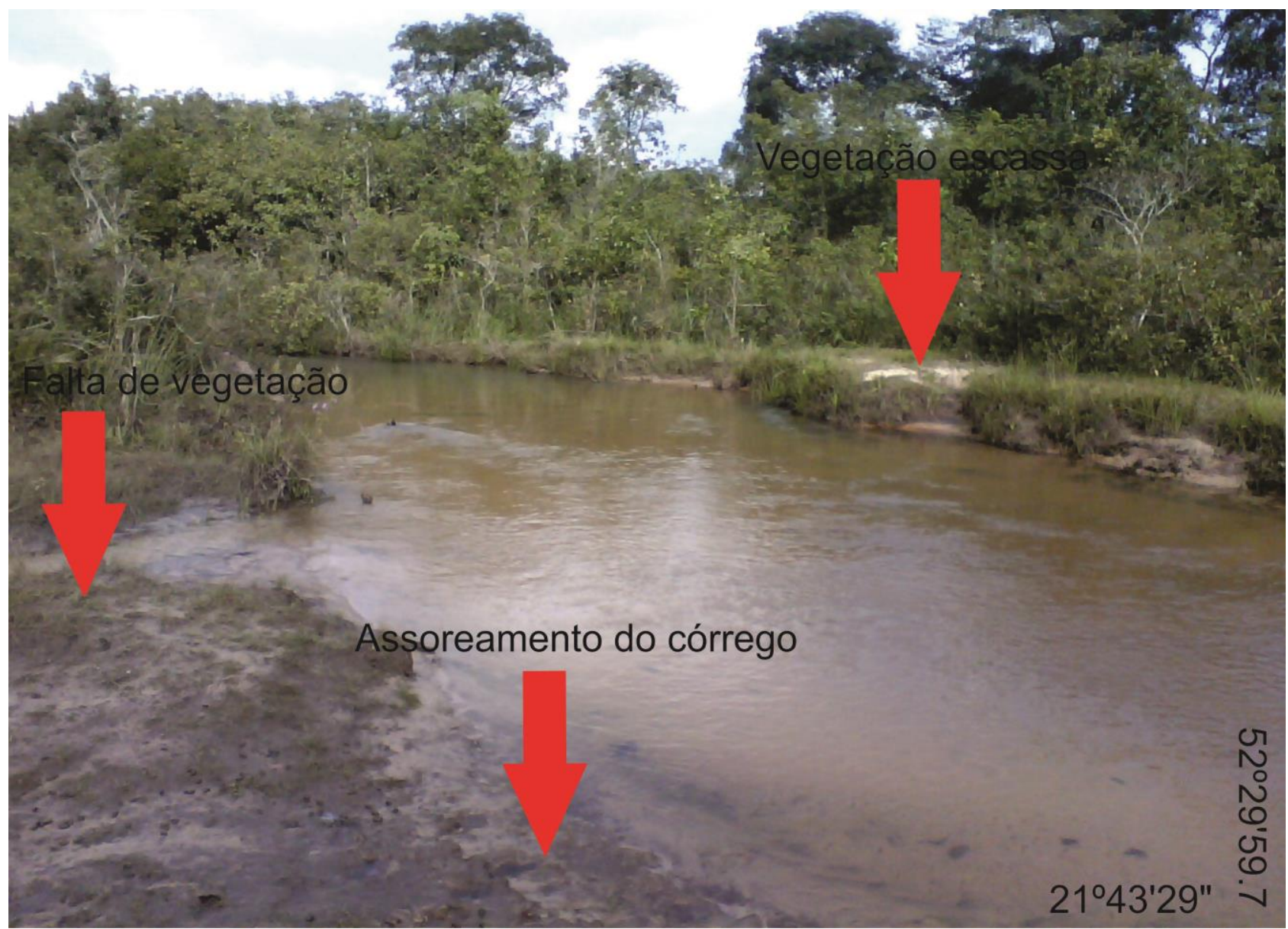

Figura 4 - Processo erosivo na bacia hidrográfica do Uerê

$\mathrm{Na}$ imagem acima é encontrado mais uma vez a falta de mata ciliar, que protegem os cursos d'água contra processos erosivos. Encontrando em outro trecho do córrego processos erosivos e assoreamento.

Medidas preventivas como recuperação da mata ciliar, como proteção dos trechos hídricos, cercamento de áreas onde-se encontra os processos erosivo evitando assim o pisoteio do gado, além da conscientização do proprietário quanto a recuperação e manutenção dessas áreas são imprescindíveis para a recuperação dessas áreas degradadas e a melhora na qualidade ambiental da bacia hidrográfica do Uerê.

\section{CONCLUSÃO}

O projeto desenvolvido pelo INPE (Instituto Nacional de Pesquisas Espaciais), o software computacional SPRING, desde seu lançamento vem evoluindo gradativamente 
no trabalho em questão utiliza-se o SPRING modelo 5.1.2, auxiliando pesquisadores em seus trabalhos, com a atualização de novos programas anualmente.

No site do INPE disponibiliza-se imagens de satélite gratuitamente (imagens dos satélites CBERS, LANDSAT, ResourceSat, entre outros), dando um impulso para que as geotecnologias expandissem nas pesquisas nacionais que utilizam dessas ferramentas.

O trabalho mostra a importância dos mapas nas análises de degradação ambiental, os mapas temáticos, geralmente utilizam outros mapas como base e tem como objetivo fornecer a representação dos fenômenos existentes sobre a superfície terrestre.

É preciso entender que as geotecnologias são ferramentas utilizadas para a produção estratégica de mapeamentos temáticos em geral. Aliando isso a um BDG, é um primeiro passo para a criação de um planejamento ambiental do local.

\section{REFERÊNCIAS}

BARROS GÓES, M.H., XAVER-DA-SILVA, J. Uma contribuição metodológica para diagnósticos ambientais por geoprocessamento. Parque Estadual de lbitipoca, Seminário de Pesquisa, 1996, Ibitipoca. Resumos... Ibitipoca: IBAMA, 1996, pp.13-23.

BERTALLANFY, L. V. Teoria Geral dos Sistemas. Petrópolis: Editora Vozes, 1977.

BOTELHO, R.G.M. Planejamento ambiental em microbacia hidrográfica. In:Erosão e Conservação dos Solos - conceitos, temas e aplicações. A.J.T. GUERRA, A.S. SILVA \& R.G.M. BOTELHO (org.). Rio de Janeiro: Bertrand Brasil, 1999.

BOTELHO, R.G.M; SILVA, A.S da. Bacia hidrográfica e qualidade ambiental. Cap.6, 2004 In: VITTE, Antônio Carlos e GUERRA, Antônio José Teixeira (org.). Reflexões Sobre a Geografia Física no Brasil. Rio de Janeiro: Bertrand Brasil, 2004.

CUNHA, S.B; GUERRA, A.J.T. A questão ambiental: Diferentes abordagens. $5^{a} e d$. Rio de Janeiro: Bertrand Brasil, 2009.

FITZ, P.R. Geoprocessamento sem complicação. São Paulo: Oficina de Textos, 2008. 
IBGE. Manual Técnico do Uso da Terra. Ed.2, n.7. Rio de Janeiro, 2006.

LEPSCH, Igo F. Formação e Conservação dos Solos. São Paulo: Oficina de Textos, 2002.

MAGALHÃES, L. Z de. Problemas ambientais de uma cidade média de Mato Grosso: o caso de Barra do Bugre. Dissertação (mestrado), Universidade Federal de Mato Grosso, Cuiabá (MT), 2007.

PARANHOS FILHO, A.C. Sensoriamento remoto ambiental aplicado: Introdução as geotecnologias. Campo Grande: Ed. UFMS, 2008.

SILVA, A.M., SCHULZ, H.E.,CAMARGO, P.B. Erosão e Hidrossedimentologia em Bacias Hidrográficas. $2^{\mathfrak{a}} \mathrm{ed}$. São Carlos: RIMA, 2007.

TOMINAGA, Lidia Keiko, SANTORO, Jair; AMARAL, Rosangela do (Orgs). Desastres Naturais: conhecer para prevenir. São Paulo; Instituto Geológico, 2009. 